
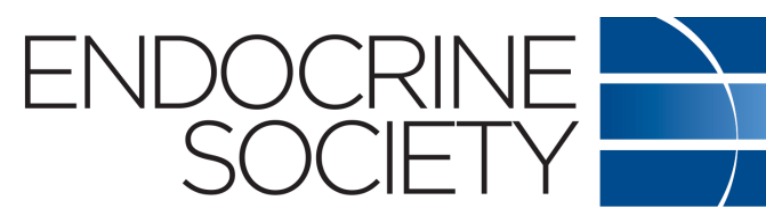

\title{
Treatment of Primary Aldosteronism with mTORC1 Inhibitors
}

Beckey Trinh, Matthias Hepprich, Matthias J. Betz, Thilo Burkard, Claudia Cavelti-Weder, Eleonora Seelig, Fabian Meienberg, Denise V. Kratschmar, Felix Beuschlein, Martin Reincke, Alex Odermatt, Michael N. Hall, Marc Y. Donath, Marta M. Swierczynska

The Journal of Clinical Endocrinology \& Metabolism

Endocrine Society

Submitted: March 08, 2019

Accepted: May 08, 2019

First Online: May 14, 2019

Advance Articles are PDF versions of manuscripts that have been peer reviewed and accepted but not yet copyedited. The manuscripts are published online as soon as possible after acceptance and before the copyedited, typeset articles are published. They are posted "as is" (i.e., as submitted by the authors at the modification stage), and do not reflect editorial changes. No corrections/changes to the PDF manuscripts are accepted. Accordingly, there likely will be differences between the Advance Article manuscripts and the final, typeset articles. The manuscripts remain listed on the Advance Article page until the final, typeset articles are posted. At that point, the manuscripts are removed from the Advance Article page.

DISCLAIMER: These manuscripts are provided "as is" without warranty of any kind, either express or particular purpose, or non-infringement. Changes will be made to these manuscripts before publication. Review and/or use or reliance on these materials is at the discretion and risk of the reader/user. In no event shall the Endocrine Society be liable for damages of any kind arising references to, products or publications do not imply endorsement of that product or publication. 
mTORC1 Inhibitors in Primary Aldosteronism

\section{Treatment of Primary Aldosteronism with mTORC1 Inhibitors}

Beckey Trinh $^{1 *}$, Matthias Hepprich ${ }^{1}$, Matthias J. Betz ${ }^{1}$, Thilo Burkard ${ }^{2}$, Claudia CaveltiWeder $^{1}$, Eleonora Seelig ${ }^{1}$, Fabian Meienberg ${ }^{3}$, Denise V. Kratschmar ${ }^{4}$, Felix Beuschlein ${ }^{5,6}$, Martin Reincke ${ }^{6}$, Alex Odermatt ${ }^{4}$, Michael N. Hall ${ }^{7}$, Marc Y. Donath ${ }^{1}$, Marta M.

Swierczynska $^{7}$

${ }^{1}$ Department of Endocrinology, Diabetes and Metabolism, University Hospital Basel and Department of Biomedicine, University of Basel, Basel 4031, Switzerland.

${ }^{2}$ ESH Hypertension Center of Excellence, Medical Outpatient Department and Cardiology, University Hospital Basel, Basel 4031, Switzerland.

${ }^{3}$ Clinic of Endocrinology and Diabetology, Kantonsspital Baselland, Liestal 4410, Switzerland.

${ }^{4}$ Department of Pharmaceutical Sciences, University of Basel, Basel 4056, Switzerland.

${ }^{5}$ Klinik für Endokrinologie, Diabetologie und Klinische Ernährung, Universitätsspital Zürich, Zürich 8091, Switzerland.

${ }^{6}$ Medizinische Klinik und Poliklinik IV, Klinikum der Universität München, Munich 80336, Germany.

${ }^{7}$ Biozentrum, University of Basel, Basel 4056, Switzerland.

ORCiD numbers:

0000-0003-2784-7079

Trinh

Beckey

0000-0002-6905-6235

Hepprich

Matthias

0000-0002-6946-1871

Betz

Matthias J.

0000-0001-6373-9820

Burkard

Thilo

0000-0002-0650-6091

Cavelti-Weder

Claudia

0000-0002-7092-1986

Seelig

Eleonora 
0000-0001-9738-8491

Meienberg

Fabian

0000-0001-7826-3984

Beuschlein

Felix

0000-0002-9817-9875

Reincke

Martin

0000-0002-6820-2712

Odermatt

Alex

0000-0002-3143-5045

Donath

Marc Y.

Received 08 March 2019. Accepted 08 May 2019.

Clinical trial registration: Clinicaltrials.gov NCT03174171

Context. mTORC1 activity is often increased in the adrenal cortex of patients with primary aldosteronism and mTORC1 inhibition decreases aldosterone production in adrenocortical cells, suggesting the mTORC1 pathway as a possible target for treatment of primary aldosteronism.

Objective. To investigate the effect of mTORC1 inhibition on adrenal steroid hormones and hemodynamic parameters in mice and in patients with primary aldosteronism.

Design. (i) Plasma aldosterone, corticosterone and angiotensin II were measured in mice treated for 24 hours with vehicle or rapamycin. (ii) Plasma aldosterone levels after a saline infusion test, plasma renin, 24-hour urine steroid hormone metabolome and hemodynamic parameters were measured during an open-label study in 12 patients with primary aldosteronism before and after two-weeks of treatment with everolimus and after a two-week washout period.

Main outcome measures. (i) Change in plasma aldosterone levels. (ii) Change in other steroid hormones, renin, angiotensin II and hemodynamic parameters.

Results. Treatment of mice with rapamycin significantly decreased plasma aldosterone levels $(P=0.007)$. Overall, treatment of primary aldosteronism patients with everolimus significantly decreased blood pressure $(P<0.05)$ and increased renin levels $(P=0.001)$ but did not lead to a significant reduction in aldosterone levels. However, prominent reduction of aldosterone levels upon everolimus treatment was observed in 4 out of 12 patients.

Conclusion. In mice, mTORC1 inhibition was associated with reduced plasma aldosterone levels. In patients with primary aldosteronism, mTORC1 inhibition was associated with improved blood pressure and renin suppression. In addition, mTORC1 inhibition appeared to reduce plasma aldosterone in a subset of patients. 
Systemic mTORC1 inhibition decreases plasma aldosterone levels in mice and in a subset of patients with primary aldosteronism.

\section{INTRODUCTION}

Primary aldosteronism (PA) is characterized by inappropriately high and relatively autonomous aldosterone production by the adrenal cortex, which results in hypertension, sodium retention, suppression of renin and increased potassium excretion. It is one of the most frequent causes of secondary hypertension (1), affecting around $6 \%$ of the general hypertensive population and up to $30 \%$ of hypertensive patients in specialized referral centers (2). The most common causes of PA are bilateral adrenal hyperplasia and aldosteroneproducing adrenal adenoma (APA).

Compared with age-, sex- and blood pressure-matched patients with essential hypertension, patients with PA have an increased risk of cardio- and cerebrovascular morbidity and mortality $(3,4)$, structural and functional renal abnormalities $(5,6)$ and metabolic syndrome (7). Targeted treatment can prevent or at least partially reverse the consequences of PA (8-10).

Depending on the subtype of PA, patient characteristics and preference, treatment comprises unilateral adrenalectomy or mineralocorticoid receptor antagonists. However, not all patients are suitable for surgery, and mineralocorticoid receptor antagonists can be associated with intolerable side effects. Therefore, additional therapeutic options are of major interest.

Although mutations in ion channels and ATPases have been identified in a high percentage of APA patients, the molecular mechanism of PA development remains poorly understood $(11,12)$. Recently, it has been demonstrated that the activity of the mammalian target of rapamycin complex 1 (mTORC1) is commonly increased in the adrenal glands of patients with PA caused by both adrenal cortex hyperplasia and aldosterone-producing adenoma (13). Furthermore, treatment of adrenocortical cells with an mTORC1 inhibitor decreases their steroid hormone production $(13,14)$ and proliferation $(13-15)$, and increases their apoptosis (16). Accordingly, mTORC1 inhibition decreases adrenocortical carcinoma growth in a mouse xenograft model (17).

Here, we analyze expression of mTORC1 components in APA and investigate whether a systemic mTORC1 inhibition affects circulating aldosterone levels, blood pressure, and renin suppression in mice and in patients with PA respectively.

\section{MATERIALS AND METHODS}

\section{Animal experiments}

All animal experiments were approved by the Kantonales Veterinäramt of Kanton BaselStadt (Basel, Switzerland). Mice were housed at $22^{\circ} \mathrm{C}$ in a conventional facility with a $12 \mathrm{~h}$ light/12 h dark cycle. 13-16 weeks old C57BL/6J, 129/SvJae, BALB/cJ mice (in-house husbandry) were injected intraperitoneally with rapamycin (LC Laboratories, $2 \mathrm{mg} / \mathrm{kg}$ of body weight) or vehicle (5\% PEG-400, 4\% ethanol, and 5\% Tween 80), and euthanized after 24 hours. Animals were injected and sacrificed between $1600 \mathrm{~h}$ and $1630 \mathrm{~h}$. Only males were used in this study.

Adrenal glands were homogenized in RIPA buffer containing Complete Proteinase Inhibitor Cocktail and PhosSTOP phosphatase inhibitor cocktail (both from Roche). Equal amounts of protein were separated by SDS-PAGE, transferred onto nitrocellulose membranes, and probed with antibodies against S6K, S6K-pThr389 (Cell Signaling, \#2780 and \#9234) and actin (Millipore, \#MAB1501).

Plasma steroid hormone levels were determined as described previously (18) and plasma AngII levels were determined using AngII ELISA kit (Biotrend). 


\section{Immunoblot and mass spectrometry analyses of APA and matched control adrenal cortex samples}

Quantification of mTORC1 activity and expression of mTORC1 components and proteins involved in mTORC1 regulation in APA and control adrenal cortex samples $(\mathrm{Ctrl})$ of the same adrenal is based on the analysis of immunoblot and mass spectrometry data obtained in the course of other investigations (19).

\section{Clinical study design and participants}

This open-label, proof-of-concept study was conducted at the University Hospital Basel between June 2017 and June 2018 and included 14 patients with PA diagnosed according to current guidelines of the Endocrine Society (2). Additional eligibility criteria included age $\geq 18$ years and an office blood pressure $<160 / 90 \mathrm{mmHg}$. Key exclusion criteria were signs of current infection, ongoing immunosuppressive treatment or documented immunodeficiency, clinically significant kidney or liver disease, uncontrolled congestive heart failure, and pregnancy or breastfeeding. Sample size was based on clinical and practical considerations for a pilot study. Due to costs, development of a true placebo was not affordable. All participants provided written informed consent after the nature and possible consequences of the study were explained. Subject characteristics are provided in Table 1.

The study was approved by the regional ethical committee (EKNZ 2015-400) and Swissmedic (2017DR2062), and was conducted in accordance with the guidelines for Good Clinical Practice and the Declaration of Helsinki. The trial was registered at Clinicaltrials.gov (NCT03174171).

\section{Intervention}

All participants received everolimus (Certican®; Novartis Pharma AG) $0.75 \mathrm{mg}$ orally twice a day (b.i.d.) for 14 days. This dosing regimen is commonly used in the clinic to prevent allograft rejection in heart and kidney transplant patients, and has a well-described safety profile.

\section{Study Assessment}

All participants attended a screening visit and 5 study visits (Figure 1). An additional visit was planned to gather histological and clinical data if adrenalectomy was performed after the last saline infusion test. The dosage of beta-blockers, central alpha-2 agonists, angiotensinconverting enzyme inhibitors, angiotensin receptor blockers and diuretics was maintained unchanged for the duration of the trial. Where applicable, subjects were taken off mineralocorticoid receptor antagonists at least 6 weeks before the baseline measurements. When required, potassium was substituted orally aiming for a serum potassium level of $\geq 3.9$ $\mathrm{mmol} / \mathrm{l}$.

Baseline measurements included standardized 7-day home blood pressure measurements (Model Omron M6 or Omron M400 ) performed as recommended by the European Society of Hypertension (20), hemodynamic measurements using the non-invasive thoracic electrical bioimpedance HOTMAN system (Hemo Sapiens Inc., San Ramon, California, USA), 24 hour urine collection for measurement of steroid hormone metabolites, baseline plasma aldosterone as assessed with standardized recumbent saline infusion test (2) and other baseline plasma steroid hormone levels as mentioned below (visit 2 and 3). The measurements were repeated after 14 days of everolimus treatment (visit 5) and after a twoweek washout period (visit 6). In addition, plasma everolimus levels were measured (visit 4, 5 and 6) to ensure medication compliance.

Plasma aldosterone, renin, cortisol, adrenocorticotropic hormone (ACTH), dehydroepiandrosterone-sulfate (DHEA-S), testosterone, (17)estradiol, everolimus level and urine creatinine were measured at the routine laboratory, Department of Clinical Chemistry, University Hospital Basel, Switzerland. Aldosterone was quantified using a competitive 
chemiluminescence immunoassay (LIAISON® Aldosterone ([REF] 310450), DiaSorin Inc., MN 55082, USA). Renin was measured by a non-competitive chemiluminescence immunoassay (LIAISON® Direct Renin ([REF] 310470), DiaSorin Inc., MN 55082, USA).

24-hour urinary steroid hormone metabolite levels [aldosterone, tetrahydroaldosterone (TH-Aldo), 18-hyroxycortisol, 18-hydroxycorticosterone, 11-deoxycortisol, cortisol (F), tetrahydrocortisol (THF), $5 \alpha$-tetrahydrocortisol ( $\alpha$-THF), cortisone $(\mathrm{E})$, tetrahydrocortisone (THE), $5 \alpha$-tetrahydrocortisone ( $\alpha$-THE), $\beta$-cortol, $\alpha$-cortolone, $\beta$-cortolone, corticosterone and 11-dehydrocorticosterone and their tetrahydro-metabolites, 11-deoxycorticosterone, dehydroepiandrosterone (DHEA), progesterone, 17 $\alpha$-hydroxyprogesterone, androsterone, $11 \beta$-hydroxyandrosterone, androstenedione and testosterone] were determined as follows: for enzymatic de-glucuronidation urinary samples $(0.5 \mathrm{ml})$ were $\mathrm{pH}$ adjusted with sodium acetate buffer $(1 \mathrm{ml}, 0.1 \mathrm{M}, \mathrm{pH} 4.3)$ and incubated $\left(2 \mathrm{~h}, 55^{\circ} \mathrm{C}\right)$ with $\beta$-glucuronidase from Helix pomatia $(80 \mu \mathrm{l}, \geq 100000 \mathrm{U} / \mathrm{ml}$; Sigma-Aldrich) prior solid-phase extraction (SPE). For extraction of free urinary steroids by SPE, de-conjungated urine samples $(1.5 \mathrm{ml})$ and nontreated urine $(1 \mathrm{ml})$ samples were diluted with sodium acetate buffer $(0.1 \mathrm{M}, \mathrm{pH} 4.3)$ containing internal standard solution (aldosterone-D7 (4 ng/ml), THF-D5 (750 ng/ml), F-D4 (300 ng/ml), E-D2 (300 ng/ml), 11-deoxycortisol-D5 (45 ng/ml), B-D8 (75 ng/ml), testosterone-D2 $(15 \mathrm{ng} / \mathrm{ml}), 17-\mathrm{OH}$-progesterone-D8 $(150 \mathrm{ng} / \mathrm{ml})$, androstenedione-D7 (45 $\mathrm{ng} / \mathrm{ml})$, DHEA-D6 (450 ng/ml), progesterone-D8 (75 ng/ml), etiocholanolone-D5 (300 $\mathrm{ng} / \mathrm{ml})$ and androsterone-D2 $(450 \mathrm{ng} / \mathrm{ml}))$ to a final volume of $2 \mathrm{ml}$. Samples were centrifuged $\left(10 \mathrm{~min}, 16000 \mathrm{x} \mathrm{g}, 4^{\circ} \mathrm{C}\right)$ and supernatants $(1.5 \mathrm{ml})$ were transferred to Oasis HBL SPE (60 mg, 3 cc; Waters) cartridges, preconditioned with ethyl acetate and water (3 ml each). Columns were washed with water/ammonium hydroxide ( 3 x $1 \mathrm{ml}, 98 / 2$, v/v), methanol/water/ammonium hydroxide $(3 \times 1 \mathrm{ml}, 20 / 78 / 2$, v/v/v) and water $(3 \times 1 \mathrm{ml})$. Steroids were eluted with ethyl acetate $(2 \times 0.75 \mathrm{ml})$, evaporated to dryness $\left(1.5 \mathrm{~h}, 35^{\circ} \mathrm{C}\right)$ and reconstituted in methanol $\left(50 \mu 1,10 \mathrm{~min}, 4^{\circ} \mathrm{C}, 1300 \mathrm{rpm}\right)$. Steroid content was analyzed by ultra-performance liquid chromatography-MS/MS (UPLC-MS/MS) using an Agilent 1290 UPLC coupled to an Agilent 6490 triple quadrupole mass spectrometer equipped with a jetstream electrospray ionization interface (Agilent Technologies). Analyte separation was achieved within $19 \mathrm{~min}$ using a reverse-phase column $(1.7 \mu \mathrm{m}, 2.1 \mathrm{~mm}$ x $150 \mathrm{~mm}$; Acquity UPLC BEH C18; Waters) and water-acetonitrile-formic acid (B: 95/5/0.1; v/v/v) and (A: $5 / 95 / 0.1 ; \mathrm{v} / \mathrm{v} / \mathrm{v})$ as mobile phases. Data acquisition and quantitative analysis was performed by MassHunter (Version B.09.00, Agilent Technologies). Tetrahydrocortisol, 5 $\alpha$ tetrahydrocortisol, tetrahydrocortisone, $\alpha$ - and $\beta$-cortolone, $\beta$-cortol, 11-deoxycortisol, cortisol and cortisone were summarized as total glucocorticoid metabolites for analysis. Small volumes and low 24-hour creatinine levels of the returned urine recorded for some patients indicated possible incomplete 24 -hour collection. To correct for this, we normalized metabolite concentrations to the 24-hour creatinine value.

\section{Study Endpoints}

The predefined primary endpoint was change in plasma aldosterone in the standard recumbent saline infusion test after 14 days of everolimus treatment as compared to baseline. Predefined secondary endpoints were changes in mean systolic and diastolic blood pressure during standardized home blood pressure measurement, change in cardiac index, changes in serum potassium level and dose of potassium substitution, changes in 24-hour urine aldosterone metabolites, and changes in plasma ACTH, renin, cortisol, DHEA-S, testosterone and (17)estradiol levels after 14 days of everolimus treatment as compared to baseline.

Considering the moderate reproducibility of plasma aldosterone in repeated saline infusion tests (21) with a difference of the means by $14 \%$, we defined responders as a reduction of $\geq 30 \%$ from baseline for our post-hoc analysis. 


\section{Statistical Analysis}

Data were analyzed using Prism v8.0 (GraphPad Software Inc). Discrete variables are expressed as counts (percentages) and continuous variables as medians with interquartile ranges (IQR). Statistical analyses were performed using Mann-Whitney test (mouse experiments) and nonparametric one-way ANOVA (Friedman) with Dunnett's post hoc test (clinical study data). $P$-value $<0.05$ was defined as significant.

\section{RESULTS}

\section{Increased activity of mTORC1 in APA is not caused by overexpression of mTORC1} components or its regulators

Previous studies, including ours, reported increased mTORC1 activity in the majority of APAs $((13,19,22)$; Figure 2A, B). To establish whether the observed increased mTORC1 activity is due to changes in expression of mTORC1 components or proteins involved in mTORC1 regulation, we analyzed the results of deep quantitative mass spectrometry analysis of 6 pairs of APA and matched control adrenal cortex samples (19). The expression of mTORC1 components was not changed in any APA analyzed (Figure 2C). Three APAs displayed increased expression of insulin receptor and/or IGF2 receptor (Figure 2D). However, these changes did not correlate with mTORC1 activity (Figure 2B). The expression of AMPK components was not altered in APAs (Figure 2E). Adenomas expressed higher levels of multiple proteins involved in $\mathrm{mTORC} 1$ stimulation in response to amino acids (Figure 2F). However, the most pronounced changes were observed in APAs not characterized by increased mTORC1 activity (Patients 1 and 4). Thus, most likely, increased expression of positive mTORC1 regulators is not the underlying cause of increased mTORC1 activity in aldosterone-producing adenomas. Further studies are required to determine whether elevated mTORC1 activity observed in most APAs is due to common changes in activities of known signaling pathways upstream of mTORC1.

\section{Systemic inhibition of mTORC1 decreases plasma aldosterone levels in mice} mTORC1 inhibition decreases steroid hormone secretion from primary adrenocortical cells and adrenocortical cell lines $(13,22)$. To assess whether mTORC1 affects adrenal steroid synthesis in vivo, we systemically treated mice with the mTORC1 inhibitor rapamycin and assessed their plasma aldosterone and corticosterone levels. Treatment with rapamycin (24 hours) reduced adrenal mTORC1 activity (Figure 3A) and significantly reduced plasma aldosterone levels $(P=0.007$, Figure 3B). Plasma corticosterone levels tended to be lower in rapamycin-treated animals, but the difference was not statistically significant (Figure 3B). Aldosterone is regulated mainly by Angiotensin II (Ang II). However, the levels of plasma Ang II did not change upon rapamycin treatment (Figure 3C). Thus, systemic mTORC1 inhibition with rapamycin reduces circulating aldosterone levels independent of Ang II. Whether rapamycin lowers plasma aldosterone levels directly by affecting aldosterone synthesis in the adrenal gland or indirectly by affecting the expression of paracrine factors regulating aldosterone synthesis and/or aldosterone metabolism requires further studies.

\section{Systemic mTORC1 inhibition with everolimus decreases plasma aldosterone levels in some primary aldosteronism patients}

To assess whether systemic mTORC1 inhibition could decrease aldosterone levels also in PA patients, we designed an open-label, proof-of-concept study on treatment of PA with the oral mTORC1 inhibitor everolimus. In this study, subjects received everolimus for two weeks and their plasma steroid hormone levels, along with other biochemical and clinical parameters, were assessed before and after treatment, as well as after a two-week washout period (Figure 1A). 14 patients with PA were enrolled, of which 12 completed the study (Figure 1B). One drop-out was due to a respiratory tract infection, and another was due to acute pancreatitis 
requiring hospitalization with full recovery without sequelae. The latter was reported as a serious adverse event probably related to everolimus. 10 subjects reported mild to moderate adverse events which were mainly skin or mucosal changes. Participant adherence was good, as reflected by detectable plasma everolimus levels during the treatment.

Median post-infusion plasma aldosterone levels were comparable at baseline, after the two-week everolimus treatment, and after the washout period (Figure 4A). However, posthoc individual subject analysis allowed identification of 4 responders defined by a $\geq 30 \%$ reduction in plasma aldosterone levels after treatment (Figure 4B). Importantly, aldosterone levels in the responder cohort returned to the baseline values after the washout period (Figure 4B), indicating the causative effect of the treatment. The effect of everolimus appears to be specific to aldosterone among the measured steroid hormones, as no similar changes were observed for cortisol (Figures 4C, D), testosterone (Figures 5A, B), DHEA-S (Figures 5C, D) or (17)estradiol (Figures 5E, F). The apparent reduction in plasma cortisol levels after the washout period (Figure 4C) was most likely an artifact due to varying stress levels at repeated visits and therefore not-treatment related. The observed changes in aldosterone were not accompanied by changes in plasma ACTH concentrations (Figures 4E, F) or serum potassium levels (Table 2). Thus, everolimus treatment appears to lower plasma aldosterone in a subset of PA patients independently of changes in ACTH or potassium concentration. There was no apparent correlation between age, gender, the severity of hypertension, the presence of hypokalemia or underlying cause of PA and everolimus response. Thus, further studies are needed to distinguish between potential responders and non-responders.

\section{Everolimus treatment influences $24 \mathrm{~h}$ urine steroid metabolome}

To distinguish whether the treatment-associated decrease in plasma aldosterone in the responder cohort resulted from the decreased synthesis or enhanced metabolism, we measured the levels of aldosterone and its major metabolite, tetrahydroaldosterone (TH-Aldo) in urine collected over 24 hours. Three responders displayed a marked decrease in urine aldosterone and TH-Aldo levels upon everolimus treatment (Figures 6A, B), suggesting reduced aldosterone synthesis. It was impossible to determine changes in urine aldosterone and TH-Aldo levels in the $4^{\text {th }}$ responder due to the loss of the baseline sample. Similar to plasma measurement, no changes in median urine aldosterone and $\mathrm{TH}$-Aldo concentrations were observed when patients were analyzed together (Figures 6A, B). Furthermore, no consistent changes in urine cortisol, total glucocorticoid metabolites, testosterone, $11 \beta$ hydroxyandrosterone, and progesterone levels were observed (Figures 6C, D, E, F, G). Additionally, no changes were observed in the levels of 11-deoxycorticosterone, 18hydroxylated cortisol and corticosterone or corticosterone and its tetrahydro-metabolites. Taken together, these data suggest that in a subset of PA patients everolimus specifically reduces aldosterone synthesis but does not show a consistent effect on other adrenal steroids, including those with mineralocorticoid effects.

\section{Everolimus treatment decreases blood pressure}

To assess whether everolimus treatment could lower blood pressure in PA patients, we asked the study participants to take standardized home blood pressure measurements during the trial. Systolic and diastolic blood pressure measurements were significantly improved after the everolimus treatment and returned to the baseline values after the washout period (Figures 7A, B). The observed changes in blood pressure were independent of changes in cardiac index (Figure 7C). Thus, everolimus treatment lowers blood pressure in hypertensive PA patients. Whether these changes are a consequence of reduced aldosterone levels requires further studies.

\section{Everolimus treatment attenuates renin suppression}


High aldosterone levels characteristic of PA lead to suppression of renin, a protease secreted by the renal glomeruli and involved in the regulation of angiotensin and aldosterone. We evaluated whether everolimus treatment would reduce renin suppression. Indeed, plasma renin concentrations were significantly increased after the everolimus treatment compared to baseline (Figure 7D, E) although still remained in the suppressed range. Heart rate (Figure 7F), urine volume (Table 2) and copeptin, a marker for stress response and antidiuretic hormone $(\mathrm{ADH})$ release, remained unchanged (Figure 7G). Thus, the effect of everolimus on plasma renin concentration appears not to be due to volume depletion. Whether this effect is due to subtle changes in aldosterone levels or the action of everolimus outside adrenal glands remains to be determined.

\section{DISCUSSION}

Plasma aldosterone levels decreased markedly after everolimus treatment and returned close to baseline after the washout period in 4 out of 12 subjects. This pattern was mirrored by changes in urinary aldosterone and TH-Aldo levels, strongly suggesting a treatment-related reduction in aldosterone synthesis in a subset of PA patients.

There may be several reasons why everolimus did not lower plasma aldosterone levels in all subjects. First, mTORC1 is hyperactivated in most, but not all, PA adrenals $(13,22)$. Second, everolimus-response might depend on the nature of molecular event leading to PA development and APAs differ considerably on a molecular level (23). While transcriptome and methylome analyses have revealed upregulation of genes involved in the Wnt signaling pathway (Figure 2A) in APAs with somatic mutations in the gene encoding KCNJ5 (23), the molecular characteristics of APAs with less frequent somatic mutations are less well described. Third, even though the genetic basis for sporadic bilateral adrenal hyperplasia is still poorly understood (24), germline variations in the KCNJ5 gene might also play a role in certain patients with bilateral adrenal hyperplasia (25). Scholl et al. have reported that certain macrolides can inhibit excessive aldosterone production caused by $\mathrm{KCNJ} 5^{\mathrm{G} 151 \mathrm{R}}$ and $\mathrm{KCNJ}^{\mathrm{L} 168 \mathrm{R}}$ mutations (26). Thus, it is plausible that everolimus, which also has a macrolide structure, might inhibit aldosterone production only in adrenocortical cells harboring particular KCNJ5 mutations or mutations in another ion channel(s). Further studies are required to correlate responsiveness to everolimus treatment with molecular characteristics of PA adrenal glands.

Although plasma aldosterone levels were prominently reduced only in 4 study participants, we observed a general reduction in median systolic and diastolic blood pressure and increased renin levels after the 2-week treatment with everolimus. It is possible that these changes were related to subtle changes in aldosterone concentrations that were not detected by standardized recumbent saline infusion test or steroid metabolome assessment in 24-hour urine. The saline infusion test might not be sensitive enough to evaluate modest changes in aldosterone synthesis as the reproducibility of the test has been reported to be moderate (21) under renin-angiotensin-aldosterone system (RAAS)-neutral therapy. Furthermore, everolimus has been reported to be associated with hypertension (27) rather than hypotension. However, it is usually used at higher doses and in combination therapies for transplant and cancer patients. Reports on the effect of everolimus alone on blood pressure and the RAAS are scarce. Alternatively, everolimus could affect the hypothalamus and sympathetic nervous system activity and consecutively lead to increased plasma renin concentration (28). It should be noted that a significant proportion of patients took beta blockers and central alpha2-agonists which lower renin levels and might have mitigated the rise in renin. Nevertheless, this would not explain the parallel fall in blood pressure. In addition, as this study was not powered to detect changes in blood pressure, a further study comprising a larger cohort and a longer treatment period is needed to elucidate potential 
effects of everolimus on the RAAS and blood pressure, and to fully understand the differences between potential responders and non-responders. Moreover, considering the potential side-effects and the finding from a recent retrospective cohort study that only an increase in plasma renin activity to $\geq 1 \mu \mathrm{g} / \mathrm{L} / \mathrm{h}$ reverses the excess risk for cardiovascular morbidity and mortality in PA as compared to essential hypertension (29), the most appropriate dosage or an mTORC1-inhibiting compound with an improved efficacy and safety profile should be investigated.

One limitation of our study is the single-arm open-label design and therefore only changes from baseline can be reported. Furthermore, the included subjects had only mild hypertension most likely due to diagnosis at earlier stages of the disease resulting from an increasing awareness for primary aldosteronism and broadened indications for screening. Therefore, the study population might not represent the historically described population with primary aldosteronism which presented most often with moderate to severe hypertension $(30,31)$.

In conclusion, we suggest that increased mTORC1 activity in APA is most likely due to downstream signaling changes rather than to overexpression of its components or canonical positive regulators. We provide evidence that mTORC1 inhibition selectively lowers aldosterone in mice and a subset of PA patients, and significantly reduces blood pressure and renin suppression in the tested patient cohort. Our findings highlight that the mTORC1 signaling pathway plays a relevant role in primary aldosteronism.

\section{ACKNOWLEDGMENTS}

We thank Susanne Rüsch for support in conducting the clinical study.

Financial support: M.N.H. and M.M.S. received funding from Novartis Foundation for Medical Biological Research, M.M.S. received funding from Novartis/University of Basel Excellence Scholarship for Life Sciences. A.O. received funding from the Swiss National Science Foundation (31003A-179400). FB and MR have been supported by the Deutsche Forschungsgemeinschaft (DFG) within the CRC/Transregio 205/1 "The Adrenal: Central Relay in Health and Disease“ and by the Else Kröner-Fresenius Stiftung (2013_A182 and 2015_A171 to MR).

Schweizerischer Nationalfonds zur Förderung der Wissenschaftlichen Forschung http://dx.doi.org/10.13039/501100001711, 31003A-179400, Alex Odermatt; Deutsche Forschungsgemeinschaft http://dx.doi.org/10.13039/501100001659, CRC/Transregio 205/1, Felix Beuschlein; Deutsche Forschungsgemeinschaft http://dx.doi.org/10.13039/501100001659, CRC/Transregio 205/1, Martin Reincke; Else Kröner-Fresenius-Stiftung http://dx.doi.org/10.13039/501100003042, 2013_A182, Felix Beuschlein; Else Kröner-Fresenius-Stiftung http://dx.doi.org/10.13039/501100003042, 2015_A171, Martin Reincke; Universität Basel http://dx.doi.org/10.13039/100008375, DBZ8682, Marta M. Swierczynska; Novartis Stiftung für Medizinisch-Biologische Forschung http://dx.doi.org/10.13039/501100004784, 16A019, Michael N. Hall

*Correspondence: Beckey Trinh, Department of Endocrinology, Diabetes and Metabolism, University Hospital Basel and Department of Biomedicine, University of Basel, Basel 4031, Switzerland, beckey.trinh@usb.ch

Disclosure summary:

The authors declare no competing interests.

\section{REFERENCES}


1. Hannemann A, Wallaschofski H. Prevalence of primary aldosteronism in patient's cohorts and in population-based studies--a review of the current literature. Horm Metab Res. 2012;44(3):157-162.

2. Funder JW, Carey RM, Mantero F, Murad MH, Reincke M, Shibata H, Stowasser M, Young WF, Jr. The Management of Primary Aldosteronism: Case Detection, Diagnosis, and Treatment: An Endocrine Society Clinical Practice Guideline. J Clin Endocrinol Metab. 2016;101(5):1889-1916.

3. Monticone S, D'Ascenzo F, Moretti C, Williams TA, Veglio F, Gaita F, Mulatero P. Cardiovascular events and target organ damage in primary aldosteronism compared with essential hypertension: a systematic review and meta-analysis. Lancet Diabetes Endocrinol. 2018;6(1):41-50.

4. Mulatero P, Monticone S, Bertello C, Viola A, Tizzani D, Iannaccone A, Crudo V, Burrello J, Milan A, Rabbia F, Veglio F. Long-term cardio- and cerebrovascular events in patients with primary aldosteronism. J Clin Endocrinol Metab. 2013;98(12):4826-4833.

5. Rossi GP, Bernini G, Desideri G, Fabris B, Ferri C, Giacchetti G, Letizia C, Maccario M, Mannelli M, Matterello MJ, Montemurro D, Palumbo G, Rizzoni D, Rossi E, Pessina AC, Mantero F, Participants PS. Renal damage in primary aldosteronism: results of the PAPY Study. Hypertension. 2006;48(2):232-238.

6. Sechi LA, Novello M, Lapenna R, Baroselli S, Nadalini E, Colussi GL, Catena C. Long-term renal outcomes in patients with primary aldosteronism. JAMA. 2006;295(22):2638-2645.

7. Fallo F, Veglio F, Bertello C, Sonino N, Della Mea P, Ermani M, Rabbia F, Federspil G, Mulatero P. Prevalence and characteristics of the metabolic syndrome in primary aldosteronism. J Clin Endocrinol Metab. 2006;91(2):454-459.

8. Wu VC, Wang SM, Chang CH, Hu YH, Lin LY, Lin YH, Chueh SC, Chen L, Wu KD. Long term outcome of Aldosteronism after target treatments. Sci Rep. 2016;6:32103. 9. Indra T, Holaj R, Strauch B, Rosa J, Petrak O, Somloova Z, Widimsky J, Jr. Longterm effects of adrenalectomy or spironolactone on blood pressure control and regression of left ventricle hypertrophy in patients with primary aldosteronism. $J$ Renin Angiotensin Aldosterone Syst. 2015;16(4):1109-1117.

10. Steichen O, Lorthioir A, Zinzindohoue F, Plouin PF, Amar L. Outcomes of drugbased and surgical treatments for primary aldosteronism. Adv Chronic Kidney Dis. 2015;22(3):196-203.

11. Boulkroun S, Fernandes-Rosa FL, Zennaro MC. Molecular and Cellular Mechanisms of Aldosterone Producing Adenoma Development. Front Endocrinol (Lausanne). 2015;6:95. 12. Lenzini L, Rossi GP. The molecular basis of primary aldosteronism: from chimeric gene to channelopathy. Curr Opin Pharmacol. 2015;21:35-42.

13. Su H, Gu Y, Li F, Wang Q, Huang B, Jin X, Ning G, Sun F. The PI3K/AKT/mTOR signaling pathway is overactivated in primary aldosteronism. PLoS One. 2013;8(4):e62399.

14. De Martino MC, van Koetsveld PM, Feelders RA, Sprij-Mooij D, Waaijers M, Lamberts SW, de Herder WW, Colao A, Pivonello R, Hofland LJ. The role of mTOR inhibitors in the inhibition of growth and cortisol secretion in human adrenocortical carcinoma cells. Endocr Relat Cancer. 2012;19(3):351-364.

15. Mariniello B, Rosato A, Zuccolotto G, Rubin B, Cicala MV, Finco I, Iacobone M, Frigo AC, Fassina A, Pezzani R, Mantero F. Combination of sorafenib and everolimus impacts therapeutically on adrenocortical tumor models. Endocr Relat Cancer. 2012;19(4):527-539.

16. de Joussineau C, Sahut-Barnola I, Tissier F, Dumontet T, Drelon C, Batisse-Lignier M, Tauveron I, Pointud JC, Lefrancois-Martinez AM, Stratakis CA, Bertherat J, Val P, Martinez A. mTOR pathway is activated by PKA in adrenocortical cells and participates in 
vivo to apoptosis resistance in primary pigmented nodular adrenocortical disease (PPNAD). Hum Mol Genet. 2014;23(20):5418-5428.

17. Doghman M, El Wakil A, Cardinaud B, Thomas E, Wang J, Zhao W, Peralta-Del Valle MH, Figueiredo BC, Zambetti GP, Lalli E. Regulation of insulin-like growth factormammalian target of rapamycin signaling by microRNA in childhood adrenocortical tumors. Cancer Res. 2010;70(11):4666-4675.

18. Strajhar P, Tonoli D, Jeanneret F, Imhof RM, Malagnino V, Patt M, Kratschmar DV, Boccard J, Rudaz S, Odermatt A. Steroid profiling in H295R cells to identify chemicals potentially disrupting the production of adrenal steroids. Toxicology. 2017;381:51-63.

19. Swierczynska MM, Betz MJ, Colombi M, Dazert E, Jenö P, Moes S, Pfaff C, Glatz K, Reincke M, Beuschlein F, Donath MY, Hall MN. Proteomic Landscape of AldosteroneProducing Adenoma. Hypertension. 2019.

20. O'Brien E, Asmar R, Beilin L, Imai Y, Mallion JM, Mancia G, Mengden T, Myers M, Padfield P, Palatini P, Parati G, Pickering T, Redon J, Staessen J, Stergiou G, Verdecchia P, European Society of Hypertension Working Group on Blood Pressure M. European Society of Hypertension recommendations for conventional, ambulatory and home blood pressure measurement. J Hypertens. 2003;21(5):821-848.

21. Solar M, Malirova E, Ballon M, Pelouch R, Ceral J. Confirmatory testing in primary aldosteronism: extensive medication switching is not needed in all patients. Eur J Endocrinol. 2012;166(4):679-686.

22. De Martino MC, Feelders RA, de Herder WW, van Koetsveld PM, Dogan F, Janssen JA, Waaijers AM, Pivonello C, Lamberts SW, Colao A, de Krijger RR, Pivonello R, Hofland LJ. Characterization of the mTOR pathway in human normal adrenal and adrenocortical tumors. Endocr Relat Cancer. 2014;21(4):601-613.

23. Murakami M, Yoshimoto T, Nakabayashi K, Nakano Y, Fukaishi T, Tsuchiya K, Minami I, Bouchi R, Okamura K, Fujii Y, Hashimoto K, Hata KI, Kihara K, Ogawa Y. Molecular characteristics of the KCNJ5 mutated aldosterone-producing adenomas. Endocr Relat Cancer. 2017;24(10):531-541.

24. Zennaro MC, Fernandes-Rosa F, Boulkroun S, Jeunemaitre X. Bilateral Idiopathic Adrenal Hyperplasia: Genetics and Beyond. Horm Metab Res. 2015;47(13):947-952.

25. Murthy M, Xu S, Massimo G, Wolley M, Gordon RD, Stowasser M, O'Shaughnessy $\mathrm{KM}$. Role for germline mutations and a rare coding single nucleotide polymorphism within the KCNJ5 potassium channel in a large cohort of sporadic cases of primary aldosteronism. Hypertension. 2014;63(4):783-789.

26. Scholl UI, Abriola L, Zhang C, Reimer EN, Plummer M, Kazmierczak BI, Zhang J, Hoyer D, Merkel JS, Wang W, Lifton RP. Macrolides selectively inhibit mutant KCNJ5 potassium channels that cause aldosterone-producing adenoma. The Journal of clinical investigation. 2017;127(7):2739-2750.

27. Bendtsen MAF, Grimm D, Bauer J, Wehland M, Wise P, Magnusson NE, Infanger M, Kruger M. Hypertension Caused by Lenvatinib and Everolimus in the Treatment of Metastatic Renal Cell Carcinoma. Int J Mol Sci. 2017;18(8).

28. Harlan SM, Guo DF, Morgan DA, Fernandes-Santos C, Rahmouni K. Hypothalamic mTORC1 signaling controls sympathetic nerve activity and arterial pressure and mediates leptin effects. Cell Metab. 2013;17(4):599-606.

29. Hundemer GL, Curhan GC, Yozamp N, Wang M, Vaidya A. Cardiometabolic outcomes and mortality in medically treated primary aldosteronism: a retrospective cohort study. Lancet Diabetes Endocrinol. 2018;6(1):51-59.

30. Monticone S, Burrello J, Tizzani D, Bertello C, Viola A, Buffolo F, Gabetti L, Mengozzi G, Williams TA, Rabbia F, Veglio F, Mulatero P. Prevalence and Clinical 
Manifestations of Primary Aldosteronism Encountered in Primary Care Practice. J Am Coll Cardiol. 2017;69(14):1811-1820.

31. Kayser SC, Deinum J, de Grauw WJ, Schalk BW, Bor HJ, Lenders JW, Schermer TR, Biermans MC. Prevalence of primary aldosteronism in primary care: a cross-sectional study. Br J Gen Pract. 2018;68(667):e114-e122.

32. Saxton RA, Sabatini DM. mTOR Signaling in Growth, Metabolism, and Disease. Cell. 2017;168(6):960-976.

33. Wolfson RL, Sabatini DM. The Dawn of the Age of Amino Acid Sensors for the mTORC1 Pathway. Cell Metab. 2017;26(2):301-309.

Figure 1. Clinical study design. (A) Study timeline. (B) Enrollment.

Figure 2. Increased activity of mTORC1 in APA is not caused by overexpression of mTORC1 components or its regulators. (A) Signaling upstream of mTORC1. mTORC1 consists of mTOR, mLST8, and RAPTOR and responds to a diverse set of inputs, most notably growth factors, amino acids, and cellular energy levels. Insulin and insulin-like growth factors (IGFs) activate mTORC1 by binding to their cognate receptors, which leads to PI3K stimulation and PDK1-dependent Akt activation. Akt phosphorylates and inactivates TSC2, a member of the TSC complex that functions as a GTPase-activating protein (GAP) toward RHEB. GTP-bound RHEB binds and activates mTORC1 (32). Amino acids stimulate mTORC1 by modulating the activity of various proteins and protein complexes that regulate RAG heterodimers. Activated RAGs recruit mTORC1 to the lysosomal surface where it interacts with RHEB. Amino acids are required for mTORC1 activation in response to any other signal (33). Energy stress (manifested as increased AMP/ATP ratio) suppresses mTORC1 signaling by activating AMPK, which in turn inhibits RAPTOR and activates the TSC complex. Bold font indicates protein complexes (32). (B) mTORC1 activity in aldosterone-producing adenomas (APAs). Levels of S6-pSer240/244, a well-established marker of mTORC1 signaling, were quantified in APA and control adrenal cortex samples (Ctrl) of the same patient by immunoblot. (C-F) Expression of (C) mTORC1 components and proteins involved in mTORC1 regulation by (D) growth factors, (E) AMPK, and (F) amino acids in APAs. Proteins were quantified in APA and matched control adrenal cortex samples by deep quantitative mass spectrometry. Proteins were considered deregulated in APA when they were differentially expressed by $>1.5$ fold $(P<0.05$, ANOVA-based $t$ test $)$ or they were detected exclusively either in Ctrl or APA samples.

Figure 3. Systemic inhibition of mTORC1 decreases plasma aldosterone levels in mice. (A) Immunoblot evaluating levels of S6K-pThr389, the activated form of S6K, and direct target of mTORC1 signaling, in adrenal glands of mice treated with vehicle or rapamycin for 24 hours. (B) Plasma aldosterone, corticosterone and (C) Angiotensin II levels in mice treated with vehicle or rapamycin for 24 hours. Data are shown as medians. $N=4$ to 8 animals per group. ** $P<0.01$ (Mann-Whitney test).

Figure 4. Systemic mTORC1 inhibition with everolimus decreases plasma aldosterone levels in some primary aldosteronism patients. (A-D) Plasma hormone levels at the baseline (V3, day 0), after a 2-week everolimus treatment (V5, day 15) and a 2-week washout period (V6, day 28). (A) Overall, post-infusion plasma aldosterone levels were not significantly changed $(P=0.436)$ after a 2 -week everolimus treatment, $($ B $)$ but a marked reduction was observed in 4 subjects shown as responders in red as opposed to nonresponders in grey. $(\mathbf{C}, \mathbf{D})$ This pattern was not observed for cortisol which was significantly lower after wash-out $(P=0.017$, post hoc adjusted $P=0.024)$. (E, F) The tendency of reduced aldosterone levels and decreased cortisol was not reflected by changes in ACTH $(P=$ 
0.320). Data are shown with median and interquartile range (IQR). Data were analyzed with nonparametric one-way ANOVA (Friedman) and Dunnett's post hoc test. $N=10$ due to missing values at V6 for subject 11 and 12 for aldosterone, $N=12$ for cortisol and ACTH. *P $<0.05$

\section{Figure 5. Systemic mTORC1 inhibition with everolimus does not influence sex}

hormones. After a 2-week everolimus treatment, no significant changes were observed in plasma testosterone $(P=0.078,(\mathbf{A})$ men, (B) women), DHEA-S $(P=0.179,(\mathbf{C})$ men, (D) women) or (17)estradiol $(P=0.843,(\mathbf{E})$ men, $(\mathbf{F})$ women). Data are shown with median and IQR. $N=12$. Data analysis with Friedman test. Subjects which showed a marked decrease of plasma aldosterone after everolimus treatment are marked as responders in red, nonresponders are marked in grey. Men and women are shown separately due to differing reference ranges and variability of sex hormones during the menstrual cylce. DHEA-S = dehydroepiandrosterone-sulfate.

Figure 6. Everolimus treatment influences $24 \mathrm{~h}$ urine steroid metabolome. Steroid hormone metabolites were normalized to 24-hour creatinine to account for possible incomplete urine collection. The 24-hour excretion of $(\mathbf{A})$ aldosterone $(P=0.629),(\mathbf{B})$ tetrahydroaldosterone $(P=0.732),(\mathbf{C})$ cortisol $(P=0.100),(D)$ total glucocorticoid metabolites (tetrahydrocortisol, $5 \alpha$-tetrahydrocortisol, tetrahydrocortisone, $\alpha$ - and $\beta$ cortolone, $\beta$-cortol, cortexolone, cortisol and cortisone; $P=0.976),(\mathbf{E})$ testosterone $(P=$ $0.470),(\mathbf{F}) 11 \beta$-hydroxyandrosterone $(P=0.470)$ and $(\mathbf{G})$ progesterone $(P=0.117)$ were not significantly different after a 2-week everolimus treatment (V5, day 15) and a 2-week washout (V6, day 28) as compared to baseline (V3, day 0). Subjects which showed a marked decrease of plasma aldosterone after everolimus treatment are marked as responders in red, non-responders are marked in grey. Data are shown with median and IQR. Data analysis with nonparametric one-way ANOVA (Friedman) and Dunnett's post hoc test. $N=11$ as baseline 24-hour urine for steroid metabolome from subject one was not collected.

Figure 7. Everolimus treatment decreases blood pressure and attenuates renin suppression. (A-B) 7-day home blood pressure measurements showed a significant decrease in systolic $(P=0.001$, adjusted $P=0.011$ day 15 vs. day 0 and $P>0.999$ day 28 vs. day 0$)$ and diastolic $(P<0.026$, adjusted $P=0.042$ day 15 vs. day 0 and $P>0.999$ day 28 vs. day 0$)$ blood pressure. $(\mathbf{C})$ Cardiac index $(P=0.179)$ was not significantly changed. $(\mathbf{D}, \mathbf{E})$ Renin increased significantly after everolimus treatment $(P<0.0001$, adjusted $P=0.001$ day 15 vs. day 0 and $P=0.023$ day 28 vs. day 0$)$. (F) heart rate $(P=0.168)$ and $(\mathbf{G})$ Copeptin $(P=$ $0.937)$ showed no significant difference. Subjects which showed a marked decrease of plasma aldosterone after everolimus treatment are marked as responders in red, non-responders are marked in grey. Data in $\mathbf{D}$ are shown with median and IQR. Data analysis with nonparametric one-way ANOVA (Friedman) and Dunnett's post hoc test. $N=10$ for blood pressure and heart rate, $N=11$ for renin due to missing data, $N=12$ for cardiac index and copeptin. $* P<$ $0.05, * * * P<0.001$.

Table 1. Demographic and clinical baseline characteristics of subjects. Discrete variables are expressed as counts with percentages (\%) and continuous variables as median with interquartile range (IQR).

\begin{tabular}{|l|l|}
\hline Characteristic & \\
\hline Sex & \\
& \\
\end{tabular}




\begin{tabular}{|c|c|}
\hline - male, $n(\%)$ & $7(58 \%)$ \\
\hline - female, $n(\%)$ & $5(42 \%)$ \\
\hline \multicolumn{2}{|l|}{ Ethnicity } \\
\hline - caucasian, $n(\%)$ & $9(75 \%)$ \\
\hline - african, $n(\%)$ & $3(25 \%)$ \\
\hline Age, years & $49(44-58)$ \\
\hline Body mass index, $\mathrm{kg} / \mathrm{m}^{2}$ & $32.6(26.3-35.4)$ \\
\hline Duration of hypertension, years & $2.5(0.25-7)$ \\
\hline 7-day home blood pressure & \\
\hline - systolic, $\mathrm{mmHg}$ & $132(129-150)$ \\
\hline - diastolic, $\mathrm{mmHg}$ & $87(80-94)$ \\
\hline Number of antihypertensive drugs, $n$ & $2.5(1-5)$ \\
\hline Lateralisation on adrenal venous sampling, $n(\%)$ & $6 / 10(60 \%)$ \\
\hline Histology & \\
\hline - aldosterone producing adenoma, $n(\%)$ & $3(25 \%)$ \\
\hline - bilateral adrenal hyperplasia, $n(\%)$ & $4(33 \%)$ \\
\hline - micronodular hyperplasia, $n(\%)$ & $3(25 \%)$ \\
\hline - unknown, $n(\%)$ & $2(17 \%)$ \\
\hline Hypokalemia, $n(\%)$ & $10(83 \%)$ \\
\hline Potassium substitution, $\mathrm{mmol} / \mathrm{day}$ & $100(60-140)$ \\
\hline Plasma aldosterone, $\mathrm{pmol} / \mathrm{l}$ & $640(504-1054)$ \\
\hline Direct renin concentration, $\mathrm{ng} / \mathrm{l}$ & $0.7(0.3-1.4)$ \\
\hline Serum potassium, $\mathrm{mmol} / \mathrm{l}$ & $4.1(3.7-4.3)$ \\
\hline GFR, $\mathrm{ml} / \mathrm{min} / 1.73$ & $100(85-108)$ \\
\hline $\mathrm{HbA} 1 \mathrm{c}, \%$ & $5.5(5.3-5.8)$ \\
\hline Total cholesterol, $\mathrm{mmol} / \mathrm{l}$ & $4.98(4.21-5.40)$ \\
\hline LDL, mmol/1 & $2.62(2.25-3.08)$ \\
\hline $\mathrm{HDL}, \mathrm{mmol} / \mathrm{l}$ & $1.40(1.16-1.54)$ \\
\hline Triglycerides, $\mathrm{mmol} / \mathrm{l}$ & $1.8(1.21-2.50)$ \\
\hline $\mathrm{CRP}, \mathrm{mg} / \mathrm{l}$ & $2.6(1.3-4.9)$ \\
\hline
\end{tabular}

Table 2. Everolimus lowers plasma aldosterone levels in some primary aldosteronism patients, decreases blood pressure and attenuates renin suppression

\begin{tabular}{|l|l|l|l|}
\hline & V 3 (day 0) & V5 (day 15) & V6 (day 28) \\
\hline Basal plasma aldosterone (pmol/l) & $640(504-1054)$ & $668(468-831)$ & $675(427-981)$ \\
\hline Direct renin concentration (ng/l) & $0.7(0.3-1.4)$ & $1.5(0.7-4.7)^{* * *}$ & $0.7(0.2-3.9)^{*}$ \\
\hline Plasma cortisol (nmol/l) & $238(185-267)$ & $214(166-298)$ & $167(139-236)^{*}$ \\
\hline ACTH $(\mathrm{pg} / \mathrm{ml})$ & $13.5(8.4-22.3)$ & $12.0(6.2-21.8)$ & $14.1(8.4-19.1)$ \\
\hline Copeptin $(\mathrm{pmol} / \mathrm{l})$ & $6(3.9-8.9)$ & $6(4.7-9.2)$ & $5.7(3.4-9.7)$ \\
\hline Serum potassium $(\mathrm{mmol} /)$ & $4.1(3.7-4.3)$ & $4.0(3.9-4.2)$ & $3.8(3.7-4.0)$ \\
\hline Potassium substitution $(\mathrm{mmol} / \mathrm{day})$ & $100(60-140)$ & $120(60-140)$ & $120(60-140)$ \\
\hline 7-day home blood pressure & & & \\
\hline
\end{tabular}




\begin{tabular}{|l|l|l|l|}
\hline$-\quad$ Systolic $(\mathrm{mmHg})$ & $132(129-150)$ & $130(125-140)^{*}$ & $134(129-149)$ \\
\hline$-\quad$ Diastolic $(\mathrm{mmHg})$ & $87(80-94)$ & $84(78-90)^{*}$ & $86(82-95)$ \\
\hline Cardiac index $\left(1 / \mathrm{min} / \mathrm{m}^{2}\right)$ & $2.5(1.6-3.4)$ & $2.7(2.4-3.3)$ & $2.5(1.5-2.9)$ \\
\hline Heart rate (beats per minute) & $55(52-68)$ & $61(54-66)$ & $63(57-66)$ \\
\hline
\end{tabular}

Comparison of baseline measurements (V3, day 0), after a 2-week treatment with everolimus (V5, day 15) and after a 2-week wash-out period (V6, day 28). Data are shown with median and IQR. $* P<0.05, * * * P<0.001$ versus baseline (Friedman test with Dunnett's post hoc test). 
A

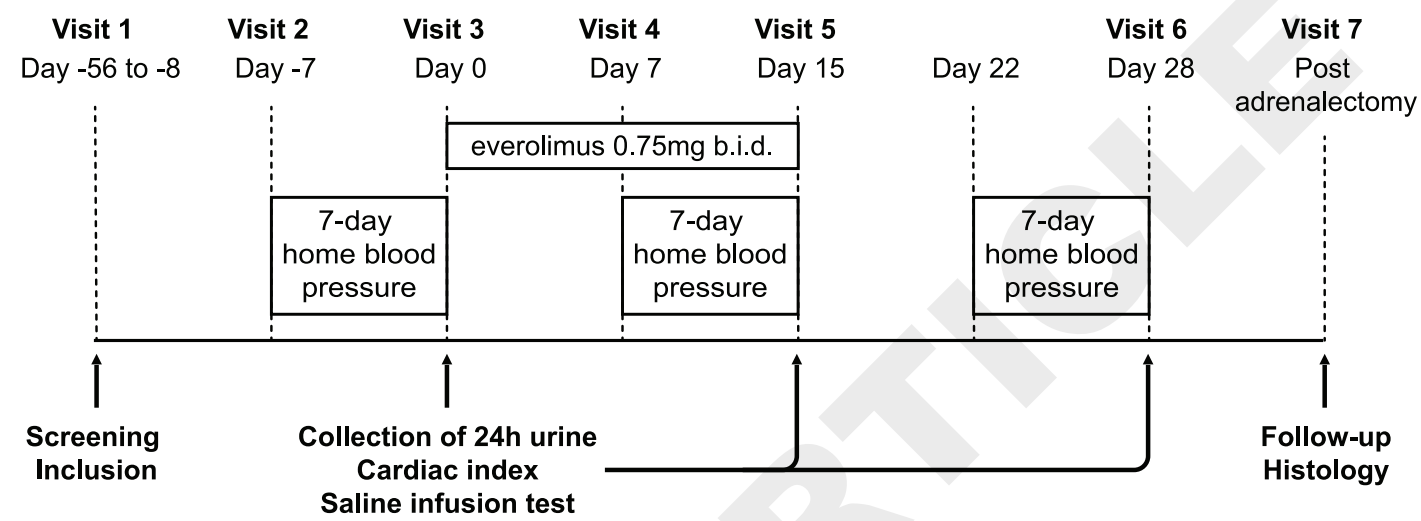

B

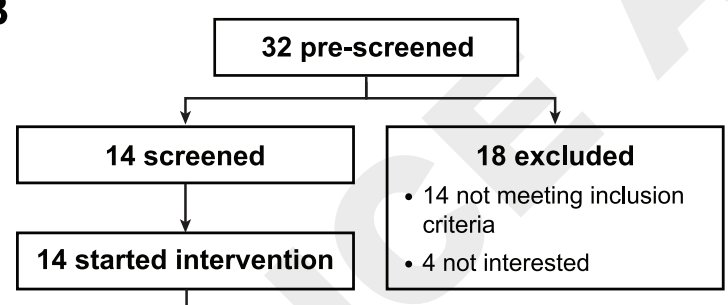

2 drop outs

- 1 respiratory infection

- 1 pancreatitis

12 completed study 


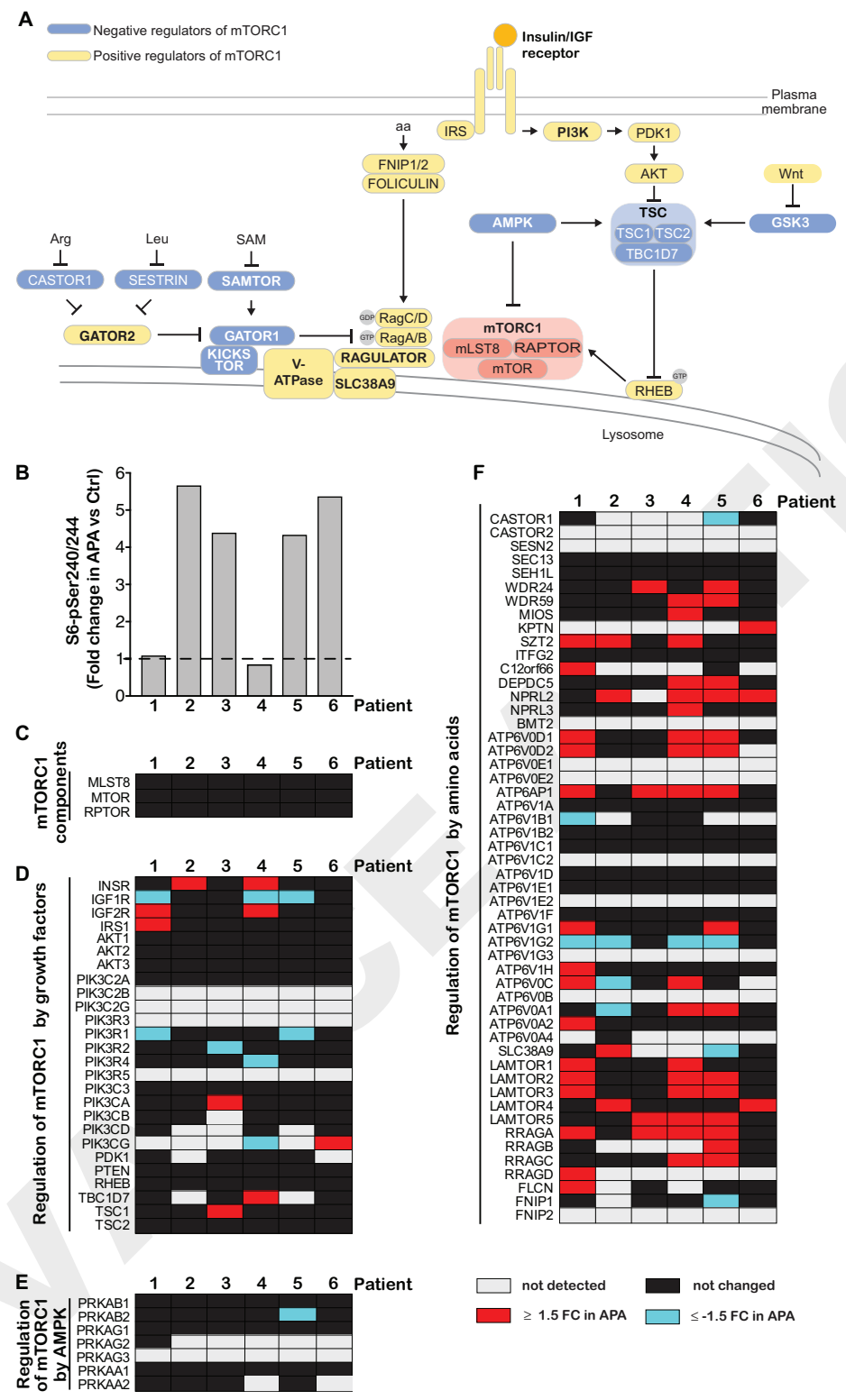



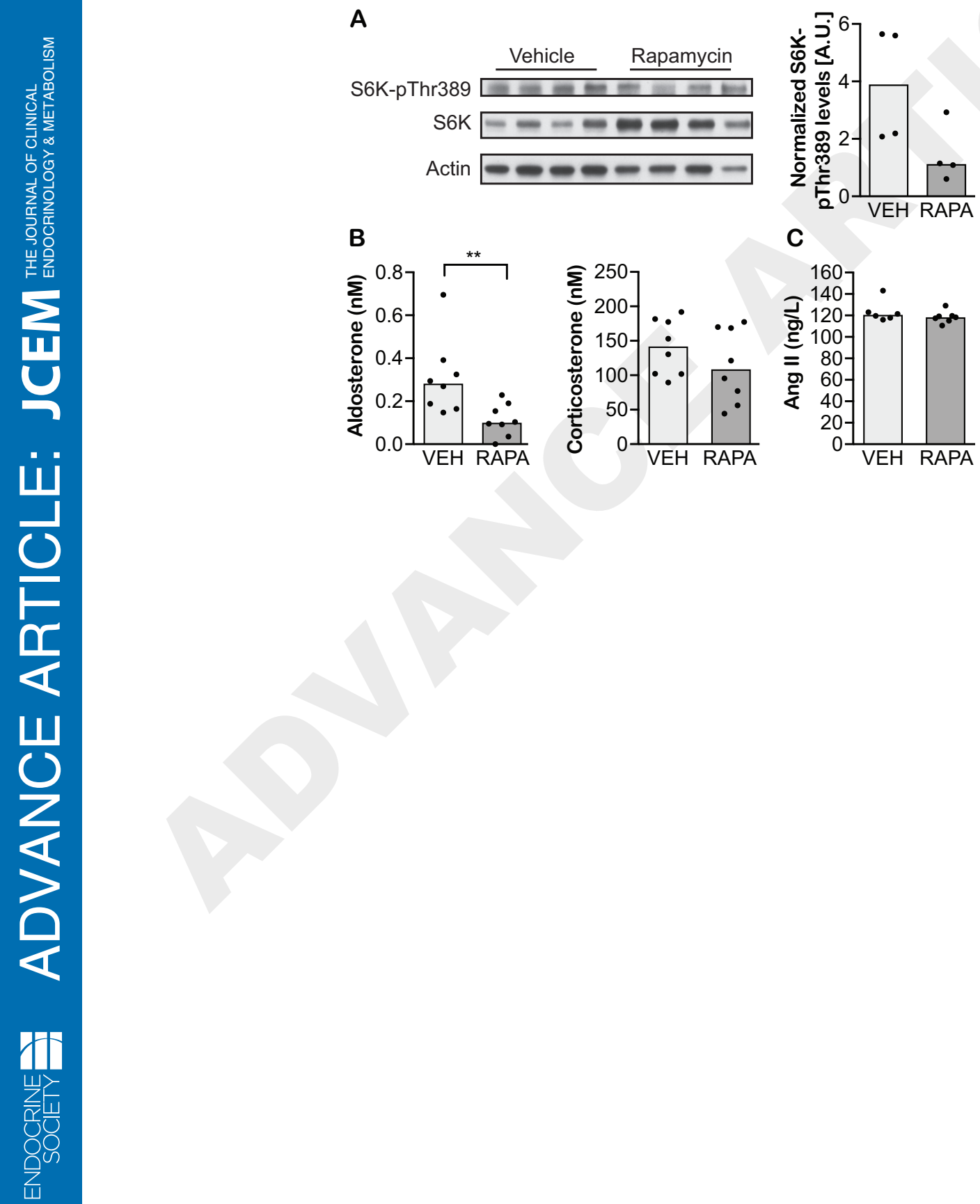

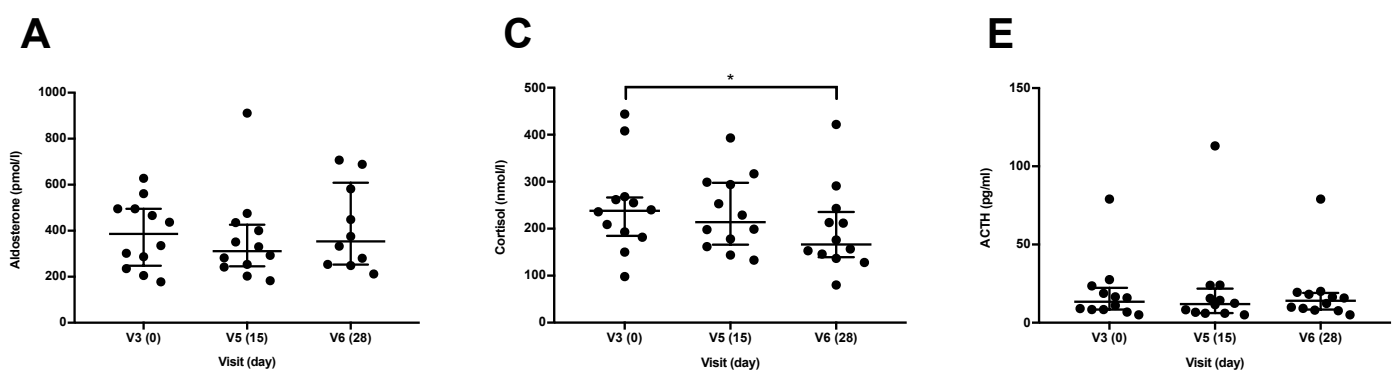

B
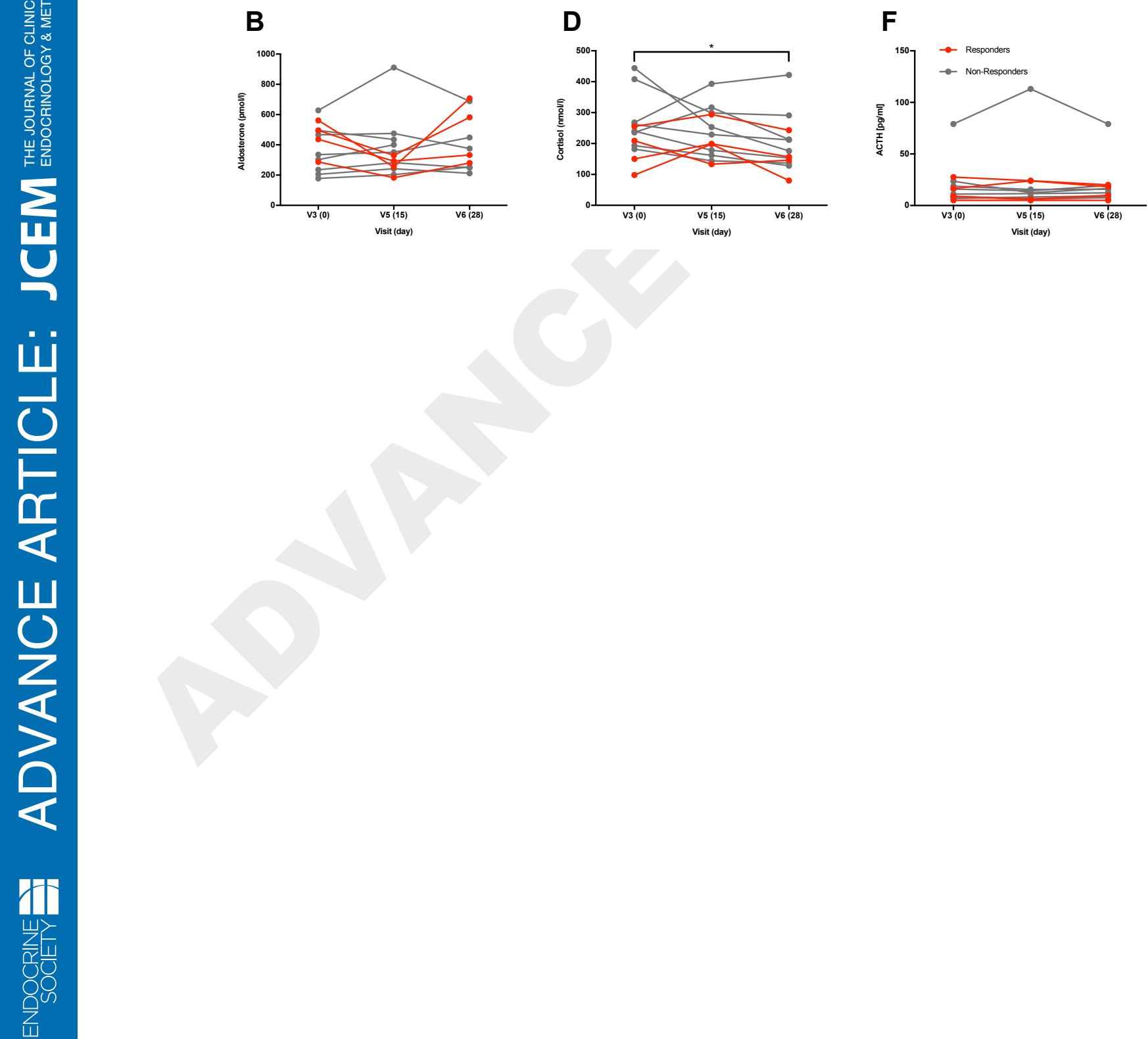

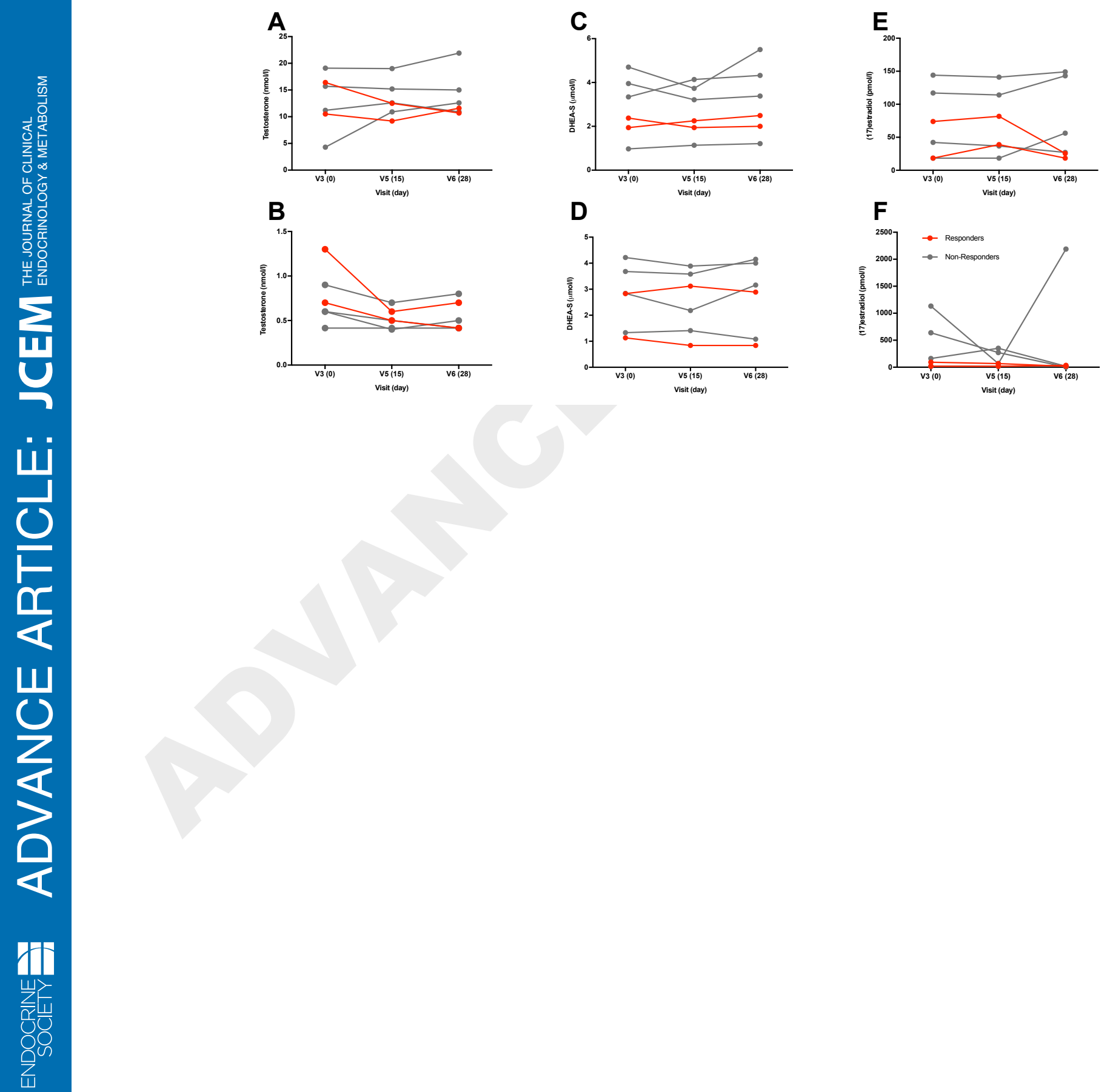

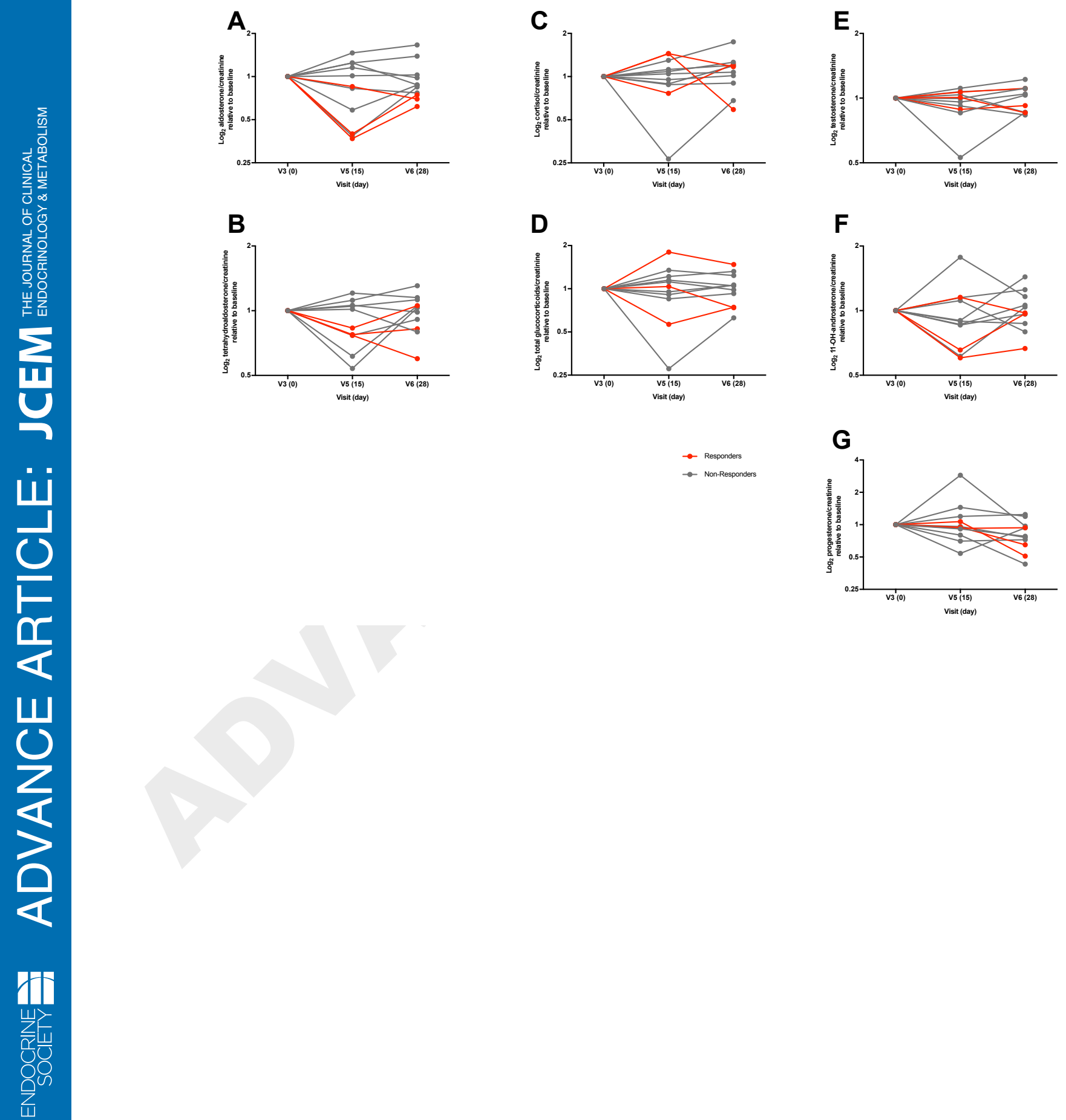


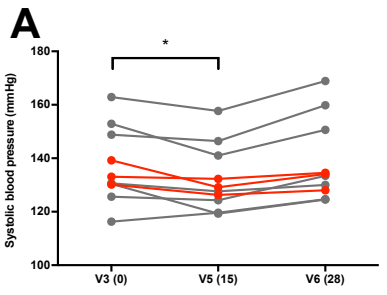

B

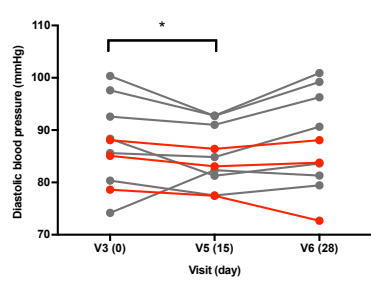

C

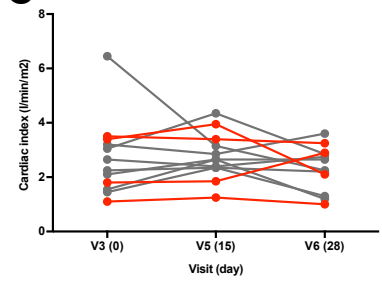

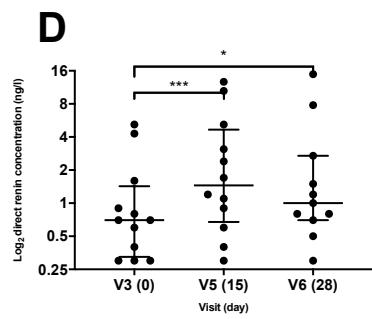

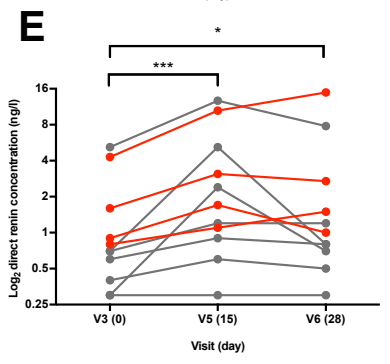

பن

0

$\frac{\dot{u}}{\dot{U}}$

山

0

II $\mathcal{U}$

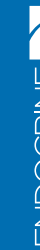

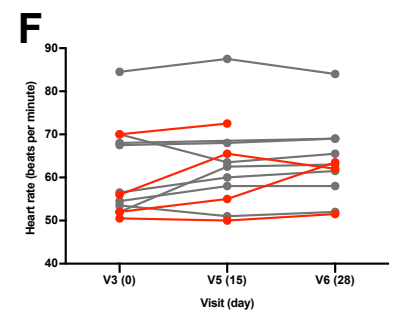

G

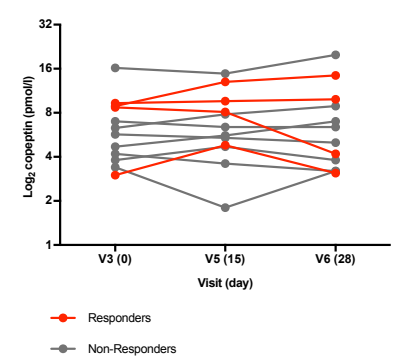

